\title{
Evidence That Glycocalicin Circulates in Normal Plasma
}

\author{
Barry S. Coller, Efstathia Kalomiris, Mark Steinberg, \\ and Lesley E. Scudder \\ Division of Hematology, Department of Medicine, \\ State University of New York at Stony Brook, \\ Stony Brook, New York 11794
}

bstract. By using a combination of a heterologous antiserum to GPIb/glycocalicin and a radiolabeled monoclonal antibody to GPIb/glycocalicin, we were able to develop a sensitive and specific radioimmunoelectrophoretic assay that can distinguish small amounts of glycocalicin from GPIb. Normal plasmas were found to contain glycocalicin, even in samples treated with protease inhibitors and centrifuged extensively to remove platelets and platelet fragments. Confirmation that the plasma antigen had a relative molecular weight similar or identical to glycocalicin was obtained from studies employing gel chromatography and affinity chromatography. An immunoradiometric assay was developed to quantify plasma glycocalicin, and normal plasma was found to contain $\sim 1-3 \mu \mathrm{g} / \mathrm{ml}$. The plasma of a patient with severe thrombocytopenia due to aplastic anemia had $<12.5 \%$ of the normal level of glycocalicin, whereas two patients with thrombocytopenia due to diseases of increased platelet destruction (idiopathic thrombocytopenic purpura and hemolytic-uremic syndrome) had normal levels. Thus, there appears to be ongoing catabolism of platelet GPIb in vivo, and we postulate that the plasma level of glycocalicin reflects a complex function of factors, including platelet count, platelet turnover, and the site of platelet destruction.

\section{Introduction}

The platelet membrane glycoprotein designated GPIb ( $M_{\mathrm{r}}$ $170,000)$ is composed of a larger $\alpha$-chain $\left(M_{\mathrm{r}} 143,000\right)$ and a smaller $\beta$-chain $\left(M_{\mathrm{r}} 23,000\right)$ held together by one or more disulfide bonds $(1,2)$. The $\alpha$-chain has a small hydrophobic portion 1983.

Received for publication 5 July 1983 and in revised form 27 October

J. Clin. Invest.

(c) The American Society for Clinical Investigation, Inc.

0021-9738/84/03/0794/06 \$1.00

Volume 73, March 1984, 794-799 that is thought to be imbedded in the membrane and a larger, carbohydrate-rich region that extends out from the membrane. The external $\left(M_{\mathrm{r}} \sim 135,000\right)$ portion of the $\alpha$-chain has been given the name glycocalicin (3); it is readily cleaved from the intact $\alpha$-chain by a variety of enzymes $(1,4)$, most notably a calcium-dependent, sulfhydryl, neutral protease(s) found in platelets $(1,5,6)$.

Based on our previous studies, which suggest that this protease may be activated during prolonged in vitro platelet aggregation (7), on evidence of selective digestion of GPIb during platelet storage in vitro (8), and on the possibility that platelets might release this enzyme into the calcium-rich plasma environment during in vivo platelet disintegration, we hypothesized that glycocalicin may circulate in vivo. To test this hypothesis, we used our previously characterized monoclonal antibody that reacts with an epitope on the glycocalicin portion of GPIb $\alpha(9)$, to develop immunoelectrophoretic and immunoradiometric assays for glycocalicin. Our data indicate that glycocalicin does, indeed, circulate in vivo in significant concentrations.

\section{Methods}

Plasma samples were prepared from whole blood drawn into either 10 $\mathrm{mM}$ sodium EDTA or $13 \mathrm{mM}$ sodium citrate. The blood was sequentially centrifuged for platelet-rich plasma (PRP), $700 \mathrm{~g}$ for $3.5 \mathrm{~min}$ at $22^{\circ} \mathrm{C}$, platelet-poor plasma, $2,000 \mathrm{~g}$ for $10 \mathrm{~min}$ at $22^{\circ} \mathrm{C}$, and platelet-free plasma, $20,000 \mathrm{~g}$ for 1 hour at $4^{\circ} \mathrm{C}$. Some platelet-free plasma was then filtered through a 0.22- $\mu \mathrm{m}$ filter (Millex-GS, Millipore Corp., Bedford, MA) and centrifuged at $100,000 \mathrm{~g}$ for $3 \mathrm{~h}$ at $22^{\circ} \mathrm{C}$. In all cases, plasma was removed carefully with a plastic pipette so as to avoid the topmost layer. All samples were tested immediately or frozen at $-20^{\circ} \mathrm{C}$. In experiments designed to minimize in vitro proteolysis, blood was drawn into a syringe containing $10 \mathrm{mM} N$-ethylmaleimide (NEM) (Aldrich Chemical Co., Inc., Metuchen, NJ), 1 mM leupeptin (Sigma Chemical Co., St. Louis, MO), $0.1 \mu \mathrm{M} \mathrm{PGE}_{1}$ (Upjohn Co., Kalamazoo, MI), and $10 \mathrm{mM}$ EDTA. In some experiments dibucaine $(1 \mathrm{mM}$; Sigma Chemical Co.) was added to PRP and incubated at $37^{\circ} \mathrm{C}$ for $3 \mathrm{~h}$ before plateletfree plasma was prepared. Polyacrylamide gel electrophoresis and staining of gels were performed as previously described (9). Silver staining was performed with the reagents from Bio-Rad Laboratories (Richmond, CA). Antibody 6D1 (a murine monoclonal antibody that blocks ris-

1. Abbreviations used in this paper: NEM, $N$-ethylmaleimide; PAS, periodic acid-Schiff; PRP, platelet-rich plasma; $P E_{1}$, prostaglandin $E_{1}$. 
tocetin-induced binding of von Willebrand factor to platelets and reacts with both glycocalicin and GPIb) was prepared and purified as previously described (9). Iodination was achieved with lactoperoxidase as previously described (9) or by chloramine $T$ using tyrosine to stop the reaction. The specific activities of the different preparations ranged from 200 to $900 \mathrm{cpm} / \mathrm{ng}$; $>90 \%$ of the radioactivity of all preparations used was precipitable with $10 \%$.trichloroacetic acid, and autoradiography of the protein preparations after sodium dodecyl sulfate (SDS)-polyacrylamide gel electrophoresis showed virtually all of the radioactivity to migrate with the intact immunoglobulin.

Immunoelectrophoresis was performed on premade $1.5 \%$ agarose gels in $35 \mathrm{mM}$ barbital buffer, pH 8.6 (Immunoelectrofilm, Kallestad Laboratories, Inc., Chaska, MN). The running buffer contained $27 \mathrm{mM}$ barbital, $23 \mathrm{mM}$ sodium acetate, and $15 \mathrm{mM}$ sodium azide. Samples $(3 \mu \mathrm{l})$ were electrophoresed at $100 \mathrm{~V}$ at $22^{\circ} \mathrm{C}$ until the bromophenol blue tracking dye placed in a well containing normal serum migrated to the 32-mm mark ( $60-100 \mathrm{~min})$. After electrophoresis, troughs were filled with $100 \mu \mathrm{l}$ of the purified heterologous anti-glycocalicin antibody, $(4.2 \mathrm{mg} / \mathrm{ml})$ to which sufficient ${ }^{125} \mathrm{I}-6 \mathrm{D} 1$ antibody was added to obtain between 50,000 and 140,000 cpm; diffusion was allowed to proceed overnight. After extensive washing in saline and a water rinse, the gels were dried and radioautography was performed with X-ray film (XAR5, Eastman Kodak Co., Rochester, NY) until the bands were visible ( $2 \mathrm{~d}-3 \mathrm{wk})$. In some experiments, the gels were stained for $5 \mathrm{~min}$ with $0.05 \%$ amido black before radioautography.

Washing and Triton X-100 solubilization of platelets for immunoelectrophoresis from citrated PRP ( $1 / 100$ vol of $40 \%$ trisodium citrate) was performed as described by Nurden et al. (10), except that the final centrifugation was at $22^{\circ} \mathrm{C}$. To estimate the quantity of glycocalicin in normal plasma, immunoelectrophoresis was performed on dilutions of a 3-M KCl extract (see below) of washed platelets resuspended to the same count as the original PRP $\left(7 \times 10^{8} / \mathrm{ml}\right)$, and on the platelet-free plasma from the same sample. The platelet pellet remaining after $\mathrm{KCl}$ extraction was solubilized in SDS and subjected to polyacrylamide gel electrophoresis; periodic acid-Schiff (PAS) staining confirmed that the extraction procedure was nearly complete, since only traces of GPIb remained.

Glycocalicin and GPIb purification. As glycocalicin is released from platelets incubated with $3 \mathrm{M} \mathrm{KCl}(4)$, presumably as a result of activation of the calcium-dependent protease(s) $(1,5,6)$, outdated platelet concentrates were so treated as the first step in glycocalicin purification. This solubilized material was further purified by two methods: first, a modification of the technique of Solum et al. (4) previously reported (9), which employed a column of wheat germ agglutinin; and second, affinity chromatography on a column of $6 \mathrm{Dl}$ antibody, elution being achieved with $0.05 \mathrm{M}$ diethylamine, $10 \mathrm{mM}$ EDTA, 0.05\% Triton X100 , and $0.05 \% \mathrm{NaN}_{3}, \mathrm{pH} 11.5$. With both purification techniques, polyacrylamide gel electrophoresis of both nonreduced and reduced samples revealed a single major PAS-positive band of $130,000 M_{r}$; usually no bands or only minor bands were visible when the same gel was stained with Coomassie Blue, but bands corresponding to the PASpositive bands were seen with silver staining. Heterologous antiserum was prepared in a New Zealand white female rabbit by intradermal injections of $\sim 50 \mu \mathrm{g}$ glycocalicin in complete Freund's adjuvant on day $1, \sim 25 \mu \mathrm{g}$ glycocalicin in incomplete Freund's adjuvant on day 13 , and $\sim 25 \mu \mathrm{g}$ glycocalicin in buffer on day $21.2 \mathrm{wk}$ after the last injection, the animal was sacrificed and $\sim 130 \mathrm{ml}$ of blood was obtained. The antiserum gave multiple precipitin arcs against normal plasma in immunoelectrophoresis, but only a single arc against lysed platelets. To remove contaminating antibodies, $45 \mathrm{ml}$ of antisera was precipitated with $50 \%$ ammonium sulfate, resuspended in $14 \mathrm{ml}$ of $10 \mathrm{mM}$ sodium phosphate buffer, $\mathrm{pH} 8$, and absorbed with $2.1 \mathrm{ml}$ normal plasma. The IgG fraction $(4.4 \mathrm{mg} / \mathrm{ml})$ was obtained by DEAE-cellulose (DE-52, Whatman Chemical Separation Inc., Clifton, NJ) chromatography and dialyzed against $0.15 \mathrm{M} \mathrm{NaCl}, 10 \mathrm{mM}$ sodium phosphate, and $0.1 \%$ sodium azide, $\mathrm{pH}$ 7.4; it gave no visible precipitin arcs with normal plasma or serum.

Partial purification of GPIb was performed on an affinity column containing $\sim 10 \mathrm{mg}$ of 6Dl antibody coupled to $6 \mathrm{ml}$ of Affigel-10 (Bio$\mathrm{Rad}$ Laboratories). Platelet concentrates ( $10 \mathrm{U})$ that were outdated, but $<40$-h-old, were pooled, made $10 \mathrm{mM}$ in EDTA, washed three times in $96.5 \mathrm{mM} \mathrm{NaCl}, 85.7 \mathrm{mM}$ glucose, $8.5 \mathrm{mM}$ Tris/Cl, $10 \mathrm{mM}$ EDTA, $\mathrm{pH} 7.4$, and lysed in $0.15 \mathrm{M} \mathrm{NaCl}, 10 \mathrm{mM}$ Tris/Cl, $20 \mathrm{mM}$ EDTA, 20 $\mathrm{mM}$ NEM, $0.05 \% \mathrm{NaN}_{3}, 1 \%$ Triton X-100, $\mathrm{pH} 7.4$, by sonication and rocking at $4^{\circ} \mathrm{C}$ for $1.5 \mathrm{~h}$. After centrifuging the sample at $12,000 \mathrm{~g}$ for $15 \mathrm{~min}$ at $4^{\circ} \mathrm{C}$ and recentrifuging the supernatant at $100,000 \mathrm{~g}$ for 90 min at $4^{\circ} \mathrm{C}$, the solubilized platelets were applied to the $6 \mathrm{D} 1$ column. The column was washed sequentially with $(a) 0.15 \mathrm{M} \mathrm{NaCl}, 0.01 \mathrm{M}$ Tris/Cl, $10 \mathrm{mM}$ EDTA, and $1 \%$ Triton X-100, pH 7.4; (b) $0.15 \mathrm{M} \mathrm{NaCl}$, $0.01 \mathrm{M}$ Tris $/ \mathrm{Cl}, 10 \mathrm{mM}$ EDTA, $0.05 \%$ Triton X-100, and $0.05 \%$ sodium azide, $\mathrm{pH} 7.4$; and $(c) 1.5 \mathrm{M} \mathrm{NaCl}, 0.05 \%$ Triton X-100, and $10 \mathrm{mM}$ EDTA, pH 7.4. GPIb was eluted with $0.05 \mathrm{M}$ diethylamine, $10 \mathrm{mM}$ EDTA, and $0.05 \%$ Triton X-100, pH 11.5. The peak tubes were pooled, dialyzed against the second wash buffer indicated above, and frozen at $-20^{\circ} \mathrm{C}$. When a nonreduced, SDS sample of the preparation was electrophoresed in a 7\% polyacrylamide gel and stained with PAS, a major band of $M_{\mathrm{r}} 155,000$, corresponding to GPIb, and a minor band of $M_{\mathrm{r}}$ 125,000 , corresponding to glycocalicin, were seen. Silver staining also showed these two bands with only minor contaminants, while Coomassie Blue failed to stain the PAS-positive bands, but did reveal minor contamination with several proteins of lower relative molecular weight. Upon reduction, a single major PAS-positive band was seen at $M_{\mathbf{r}}$ 130,000 , and a weak band appeared at $M_{\mathrm{r}} 23,000$. In both nonreduced and reduced samples, a weak PAS-positive band was seen at or near the dye front, which may correspond to the $M_{\mathrm{r}} 20,000$ protein that we previously found to copurify with GPIb (9).

Immunoradiometric assay. To quantify $6 \mathrm{D} 1$-reactive antigen in plasma, an immunoradiometric assay was adapted from the enzymelinked immunosorbent assay described by Michelson et al. (11). It is based on the principle that $6 \mathrm{Dl}$ antibody that reacts with plasma antigen will subsequently be unable to bind to GPIb on platelets. In brief, 25$\mu l$ samples of citrated PRP $\left(2 \times 10^{8}\right.$ platelets $\left./ \mathrm{ml}\right)$ or platelet-free plasma (control) were added to an appropriate number of wells of a 96-well microtiter plate, the bottoms of which consisted of $0.22-\mu \mathrm{m}$ filters (GV milliliter plate, Millipore Corp.). After a few seconds to permit spreading, the plasma was drawn through the membranes by vacuum with a manifold (Millipore Corp.) and the immobilized platelets were washed twice with $200 \mu$ l of phosphate buffer containing albumin $(0.15 \mathrm{M} \mathrm{NaCl}, 0.01$ $\mathrm{M}$ sodium phosphate, $1 \%$ bovine serum albumin, and $0.05 \% \mathrm{NaN}_{3}$ ). In a separate round-bottomed, plastic microtiter plate, $200 \mu \mathrm{l}$ of plasma or dilutions of plasma made in the above buffer were incubated with 5 $\mu \mathrm{l}$ of ${ }^{125} \mathrm{I}-6 \mathrm{D} 1$ antibody containing $6-15 \times 10^{3} \mathrm{cpm}$ for $20 \mathrm{~min}$ at $21^{\circ} \mathrm{C}$. This mixture was then added to the wells containing platelets and allowed to incubate an additional $3 \mathrm{~h}$ at $21^{\circ} \mathrm{C}$ with gentle rotation (Tektator $\mathrm{V}$, American Scientific Products, McGaw Park, IL). Each well was then dried by vacuum, washed five times with $100 \mu$ l of the above buffer, and five times with $100 \mu \mathrm{l}$ of the above buffer in which $0.05 \%$ Tween 20 (Sigma Chemical Co.) was substituted for the albumin. After a final vacuum drying, the membranes were punched out from the bottom of the wells and counted in a gamma counter. Data were analyzed by 
subtracting the $\mathrm{cpm}$ of membranes coated with platelet-free plasma (control) from those to which platelets were attached, and then plotting the results of the net $\mathrm{cpm}$ bound as a function of the plasma dilution (neat to $1 / 32$ ) on $\log -\log$ paper (Fig. 1). A straight line was usually obtained for the dilutions ranging from neat to $1 / 8$ or $1 / 16$. When eight replicates were performed at each dilution, the coefficients of variation averaged 7.95\% (Fig. 1).

Gel chromatography of plasma and $\mathrm{KCl}$ extract. To obtain an indication of the molecular size of the immunoreactive material in plasma and to compare it with glycocalicin in $\mathrm{KCl}$ extracts, both plasma $(3 \mathrm{ml})$ and a $\mathrm{KCl}$ extract $(3 \mathrm{ml}$ of a $1 / 10$ dilution prepared in column buffer, $\mathrm{OD}_{280}=0.093$ ) were chromatographed on a $69 \times 1.25$-cm column of Sephacryl S-300 (Pharmacia Fine Chemicals, Piscataway, NJ). The plasma was obtained by centrifuging whole blood drawn into a syringe containing $10 \mathrm{mM}$ EDTA, $10 \mathrm{mM}$ NEM, $1 \mathrm{mM}$ leupeptin, and $0.1 \mu \mathrm{m}$ $\mathrm{PGE}_{1}$ at $3,000 \mathrm{~g}$ for $20 \mathrm{~min}$ at $4^{\circ} \mathrm{C}$ and then at $100,000 \mathrm{~g}$ for $1 \mathrm{~h}$ at $4^{\circ} \mathrm{C}$. Elution was carried out at $4^{\circ} \mathrm{C}$ with a buffer of $0.2 \mathrm{M} \mathrm{NaCl}, 0.01$ $\mathrm{M}$ Tris/Cl, $2 \mathrm{mM}$ EDTA, and $0.05 \%$ sodium azide, $\mathrm{pH} 7.4$, at a rate

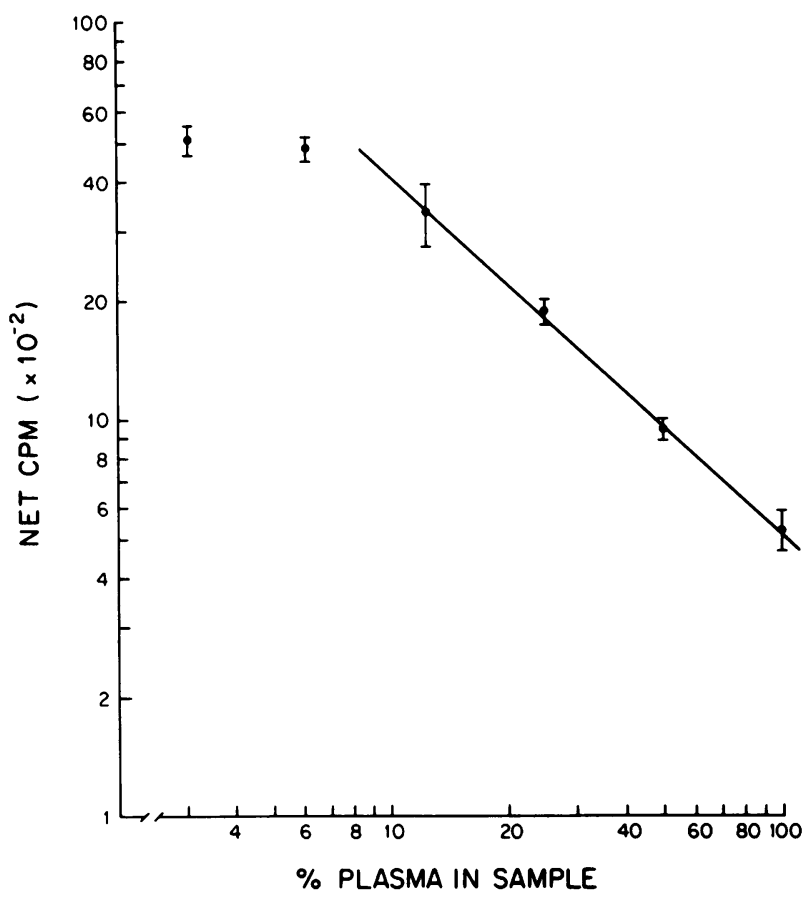

Figure 1. Log-log plot of results of immunoradiometric assay. ${ }^{125} \mathrm{I}$ 6D1 antibody was preincubated with dilutions of a pool of normal platelet-free plasmas and then reacted with platelets immobilized on a filter. After suitable washing, the radioactivity associated with the filters was determined and the net radioactivity was calculated by subtracting the radioactivity associated with filters precoated with platelet-free plasma from that of filters precoated with PRP. Radiolabeled antibody that binds to antigen in the plasma cannot bind to the GPIb on the platelets in the second step. Thus, the greater the concentration of antigen in the plasma, the lower the radioactivity bound to the filters. Each point represents the mean $\pm S D$ of eight replicate samples at each dilution. The relationship between the $\log$ of the net cpm and the log of plasma concentration was essentially linear from neat plasma to plasma diluted $1 / 8$.

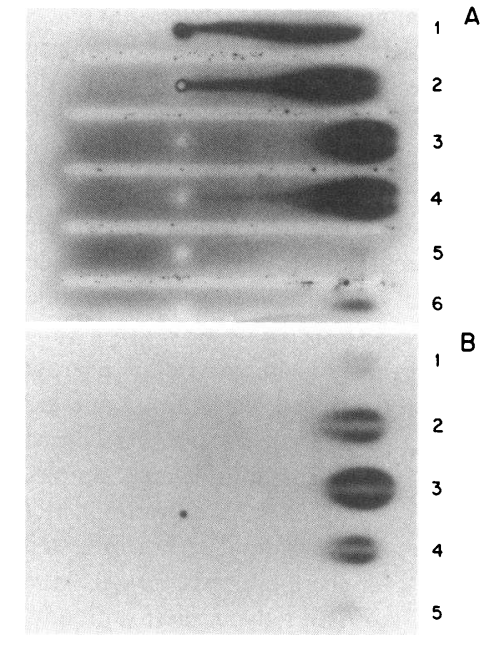

Figure 2. Radioautographs of samples electrophoresed in $1.5 \%$ agarose and then developed overnight against a combination of heterologous anti-glycocalicin antibody and ${ }^{125} \mathrm{I}-6 \mathrm{DI}$ antibody. (A) Wells contain (I) whole platelets solubilized in Triton X-100, (2) purified GPIb, (3) $3 \mathrm{M} \mathrm{KCl}$ extract of platelets, (4) purified glycocalicin, (5) plasma from a patient with aplastic anemia, and (6) plasma from a normal donor prepared from whole blood drawn into a syringe containing EDTA, NEM,

$\mathrm{PGE}_{1}$, and leupeptin, and centrifuged repeatedly, including $100,000 \mathrm{~g}$ for $3 \mathrm{~h}$. (B) Wells contain (I) normal citrated platelet-free plasma, (2) the supernatant of citrated PRP treated with dibucaine for $3 \mathrm{~h}$ at $37^{\circ} \mathrm{C}$, (3) $3 \mathrm{M} \mathrm{KCl}$ platelet extract, (4) the supernatant of citrated PRP subjected to freezing and thawing thrice, and (5) EDTA-treated platelet-free plasma.

of $2 \mathrm{ml} / \mathrm{h}$. Fractions $(2 \mathrm{ml})$ were assayed by absorbance at $280 \mathrm{~nm}$, polyacrylamide gel electrophoresis, and 6D1 immunoreactivity by both immunoradiometric assay and immunoelectrophoresis.

$6 D 1$ affinity chromatography of plasma. Plasma $(100 \mathrm{ml})$ was prepared from blood dripped into a flask containing $10 \mathrm{mM}$ EDTA, $10 \mathrm{mM}$ $\mathrm{NEM}, 0.04 \mathrm{mM}$ leupeptin, and $0.1 \mu \mathrm{M} \mathrm{PGE}_{1}$ by centrifugation at 5,000 $g$ twice for $20 \mathrm{~min}$, and $65,000 \mathrm{~g}$ twice $\left(1\right.$ and $1.5 \mathrm{~h}$ ), all at $4^{\circ} \mathrm{C}$. The plasma was passed over the $6 \mathrm{Dl}$ column at $5 \mathrm{ml} / \mathrm{h}$, after which the column was washed with $(a) 0.15 \mathrm{M} \mathrm{NaCl}, 0.01 \mathrm{M}$ EDTA, and 0.01 $\mathrm{M}$ Tris/Cl, $\mathrm{pH} 7.4 ;(b) 1.5 \mathrm{M} \mathrm{NaCl}, 0.01 \mathrm{M}$ EDTA, and $0.01 \mathrm{M}$ Tris/ $\mathrm{Cl}$, pH 7.4; and (c) $0.05 \mathrm{M}$ diethylamine and 0.01 M EDTA, pH 11.5. The last buffer eluted a protein peak that was then dialyzed against the initial wash buffer and subjected to polyacrylamide gel electrophoresis and chromatography on the Sephacryl S-300 column.

\section{Results}

Radioimmunoelectrophoresis. Fresh, washed platelets that were solubilized in Triton X-100 gave a single broad radioactive arc that began at the sample application well, increased in intensity more anodally, and ended at a location that corresponded to the middle of the albumin peak seen in serum samples run in neighboring wells (Fig. $2 \mathrm{~A}$ ). Purified GPIb gave a very similar arc (along with a minor, more anodal arc corresponding to the small amount of contaminating glycocalicin; see below). In contrast, the 3-M KCl extract of platelets gave a narrower radioactive arc with a more anodal migration, beginning at a position near the end of the GPIb arc and extending to a position near the end of the corresponding albumin peak. Purified glycocalicin gave a similar arc (along with a minor, less anodal arc corresponding to where a glycocalicin proteolysis product migrates; data not shown). 
Plasma samples from eight normal donors all revealed radioactive arcs corresponding in location to those given by the 3-M KCl extract and the purified glycocalicin. No arcs corresponding in location to those given by solubilized platelets or purified GPIb were identified. There were no qualitative differences between blood drawn into citrate, EDTA, or EDTA, $\mathrm{NEM}, \mathrm{PGE}_{1}$, and leupeptin. Moreover, there were no differences between blood centrifuged at $2,000 \mathrm{~g}$ for $10 \mathrm{~min}$ and blood that was both centrifuged for longer times at greater centrifugal force (including $100,000 \mathrm{~g}$ for $3 \mathrm{~h}$ ) and passed through a $0.22-\mu \mathrm{m}$ filter. In fact, uncentrifuged PRP did not give a more intense glycocalicin arc than platelet-free plasma; the PRP sample did, however, show increased radioactivity associated with the application well. In contrast, the plasma from a patient with severe aplastic anemia and a platelet count of $6,000 / \mu \mathrm{l}$ gave only the faintest hint of a glycocalicin precipitin arc, even with prolonged exposure (lane 5 , Fig. $2 \mathrm{~A}$ ).

The glycocalicin arc was enhanced in plasma prepared from citrated PRP that was either treated with dibucaine, a local anesthetic known to cause the digestion of GPIb (7), or subjected to freezing and thawing three times before being centrifuged at $20,000 \mathrm{~g}$ for $60 \mathrm{~min}$ at $4^{\circ} \mathrm{C}$ (Fig. $2 \mathrm{~B}$ ). The study comparing the glycocalicin content of platelet-free plasma and a $3-\mathrm{M} \mathrm{KCl}$ extract of the platelets from the same PRP sample showed that the platelet-free plasma glycocalicin arc was more intense than the $1 / 4$ dilution of the $3-\mathrm{M} \mathrm{KCl}$ extract, but less intense than the $1 / 2$ dilution. We therefore estimated it at $\sim 1 / 3$, which would be equivalent to the glycocalicin that could be extracted from $\sim 2.33$ $\times 10^{8}$ platelets $/ \mathrm{ml}$. If one estimates that there are $\sim 26,000$ GPIb sites per platelet (9), these data suggest that the glycocalicin content of plasma is $\sim 10 \mathrm{nM}$ or $\sim 1.5 \mu \mathrm{g} / \mathrm{ml}$.

Immunoradiometric assay. Preliminary studies showed that the plasmas from all normals tested contained antigen identifiable by the assay, even when the plasma was prepared from whole blood collected into a syringe containing $10 \mathrm{mM}$ EDTA, $10 \mathrm{mM}$ NEM, $1 \mathrm{mM}$ leupeptin, and $0.1 \mu \mathrm{M} \mathrm{PGE}_{1}$ by centrifugation at $100,000 \mathrm{~g}$ for $2 \mathrm{~h}$. In fact, plasma prepared by drawing blood into a syringe containing $10 \mathrm{mM}$ EDTA and centrifuging thrice at $12,000 \mathrm{~g}$ for $5 \mathrm{~min}$ at $22^{\circ} \mathrm{C}$ gave identical results to those obtained with the combination indicated above. A pool of plasmas obtained from 19 separate individuals was prepared from blood anticoagulated with $10 \mathrm{mM}$ EDTA and centrifuged thrice $(3,000 \mathrm{~g}$ for $20 \mathrm{~min}, 20,000 \mathrm{~g}$ for $10 \mathrm{~min}$, and $20,000 \mathrm{~g}$ for $10 \mathrm{~min}$, all at $4^{\circ} \mathrm{C}$ ). The pool was frozen at $-20^{\circ} \mathrm{C}$ and used as the standard for each of the assays. 13 of the plasmas making up the pool were assayed separately and found to contain $99 \pm 34 \%$ (mean $\pm S D$; range $52-156 \%$ ) of the pool value. Dilution curves of individual members of the pool were parallel to that of the pool itself. The glycocalicin antigen content of the pool of normal plasma was quantified by comparison with both a $\mathrm{KCl}$ extract of $5 \times 10^{9}$ platelets $/ \mathrm{ml}$ and with a purified preparation of GPIb/glycocalicin that contained $128 \mu \mathrm{g} / \mathrm{ml}$ of protein by an assay according to Lowry. The pool contained $1.2 \mu \mathrm{g} / \mathrm{ml}$ of glycocalicin antigen when judged against the former and 3 $\mu \mathrm{g} / \mathrm{ml}$ when judged against the latter. Both are in good agreement with the value $(1.5 \mu \mathrm{g} / \mathrm{ml})$ estimated from the immunoelectrophoresis experiment. In contrast to normal plasma, the plasma from a patient with aplastic anemia and a platelet count of $6,000 / \mu 1$ did not contain enough antigen to be assayed in the linear portion of the assay curve $(<12.5 \%)$. Estimation of the amount of antigen present from the nonlinear portion of the curve ranged from 3.5 to $11 \%$ of normal. Plasma obtained from a 12-yr-old male with acute idiopathic thrombocytopenic purpura and a platelet count of $3,000 / \mu$ l contained $68 \%$ of normal, and that of a 6-yr-old male with hemolytic-uremic syndrome (microangiopathic hemolytic anemia and azotemia) with a platelet count of $25,000 / \mu \mathrm{l}$ contained $128 \%$ of normal. Thus, the plasma glycocalicin level is not simply a reflection of the peripheral platelet count.

Gel chromatography of plasma and $\mathrm{KCl}$ extract. The $\mathrm{KCl}$ extract contained very little material that absorbed at $280 \mathrm{nM}$ (Fig. 3). Material rich in immunoreactivity eluted well after the void volume, with peak elution at $70 \mathrm{ml}$. Plasma gave a characteristic $280-\mathrm{nm}$ absorption pattern with three peaks corresponding to IgM, IgG, and albumin as judged by polyacrylamide gel electrophoresis. Immunoreactive material eluted between the IgM and IgG peaks and peak elution occurred at $70 \mathrm{ml}$, coinciding precisely with the peak found with the $\mathrm{KCl}$ extract. The shape of the peak differed slightly from that of the $\mathrm{KCl}$ extract, but the shift, if any, was less than a single tube. The total amount of antigen recovered from the plasma peak represented more than $70 \%$ of that applied. The peak tubes were tested in the immunoelectrophoresis system and found to be positive, with arcs corresponding to the position of glycocalicin.

6Dl affinity chromatography of plasma. The PAS stain of the nonreduced polyacrylamide gel of the material eluted by diethylamine showed a major band of $M_{\mathrm{r}} \sim 125,000$, along with a diffuse band at $M_{\mathrm{r}} 80-88,000$ (Fig. 4, lane $A$ ). Upon reduction, the $M_{\mathrm{r}} 125,000$ band remained essentially unchanged, whereas the $M_{\mathrm{r}} \sim 85,000$ decreased in intensity and a new band of $M_{\mathrm{r}}$ 40,000 appeared (lane $B$ ). The $M_{\mathrm{r}} 125,000$ band corresponds in migration to the glycocalicin found in a $3-\mathrm{M} \mathrm{KCl}$ extract (lane $C$ ), which had the same migration nonreduced and reduced. As is characteristic of glycocalicin, Coomassie Blue staining of the same gels revealed that all the $M_{\mathrm{r}} 125,000$ bands were associated with only weakly staining protein bands. In contrast, the $M_{\mathrm{r}} 80-88,000$ bands on both the nonreduced and reduced gels and the $M_{\mathrm{r}} 40,000$ band on the reduced gel corresponded to intensely staining protein bands (data not shown). The Coomassie Blue stain also showed significant amounts of IgG, as judged by the characteristic changes in relative molecular weight with reduction. When the eluted material was chromatographed on the Sephacryl S-300 column, the immunoreactive material eluted with a single peak that corresponded in location to that from the $\mathrm{KCl}$ extract.

\section{Discussion}

The cleavage of glycocalicin from GPIb by a variety of proteases, including one or more calcium-dependent proteases from plate- 


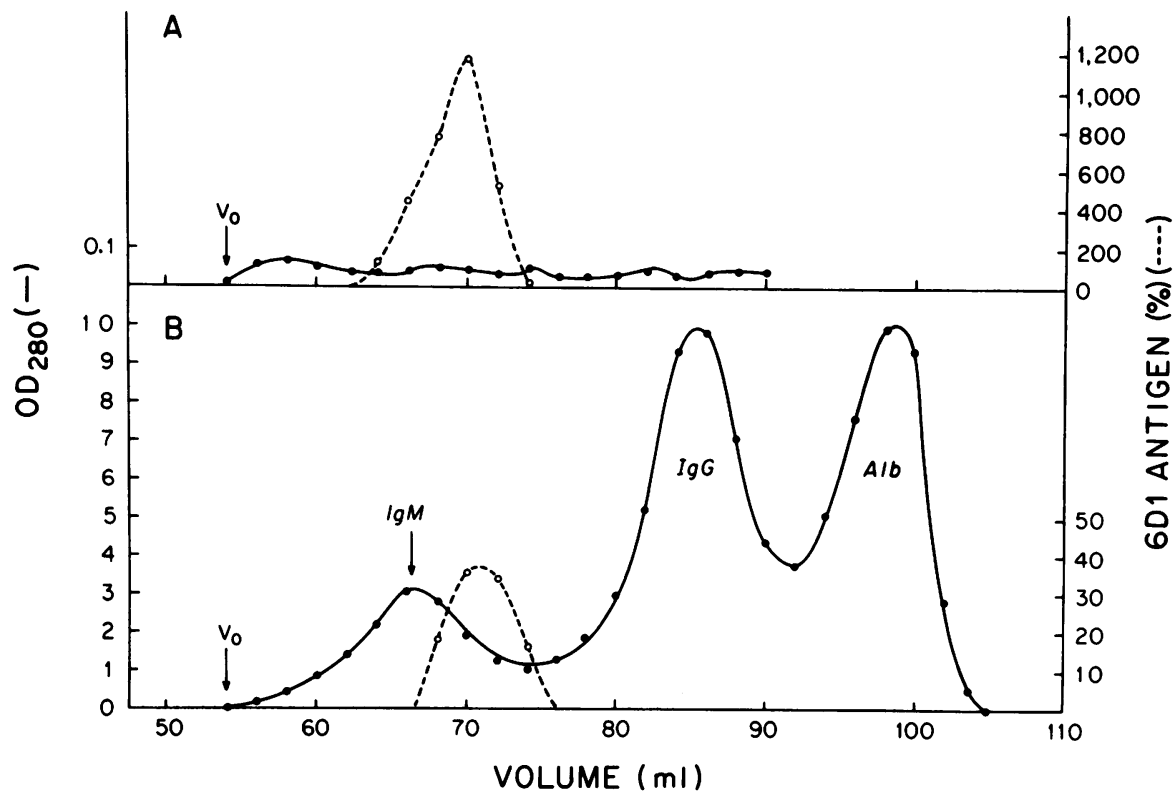

Figure 3. Elution profiles of protein (absorbance at $280 \mathrm{~nm}$ ) and 6D1-reactive antigen from a column of Sephacryl S-300. 3-ml samples of a $\mathrm{KCl}$ extract of platelets $(A)$ and normal platelet-free plasma $(B)$ were chromatographed on a $69 \times 1.25-\mathrm{cm}$ column at $2 \mathrm{ml} / \mathrm{h}$. Elution was with $0.2 \mathrm{M}$ $\mathrm{NaCl}, 0.01 \mathrm{M}$ Tris/Cl, 2 mM EDTA, $0.05 \%$ sodium azide, $\mathrm{pH} 7.4$, and $2-\mathrm{ml}$ fractions were collected. The void volume of the column is indicated. lets, has been demonstrated by several different groups $(1,4,6$, 7). If such a calcium-dependent enzyme were to be released from disintegrating platelets into the calcium-rich plasma milieu, it could act either on GPIb extending out from the platelet surface or, if GPIb were involved in adhesion, on GPIb molecules attached simultaneously to the subendothelium and the platelet. In the former case, glycocalicin would be set free into the circulation, while in the latter case, the platelet could be set free from the surface to reenter the circulation. In vitro analogues of such a process may include prolonged incubation of platelet concentrates at room temperature (8), activation of the calciumdependent enzyme(s) by local anesthetics (7), and the reversibility of von Willebrand factor-dependent platelet agglutination with

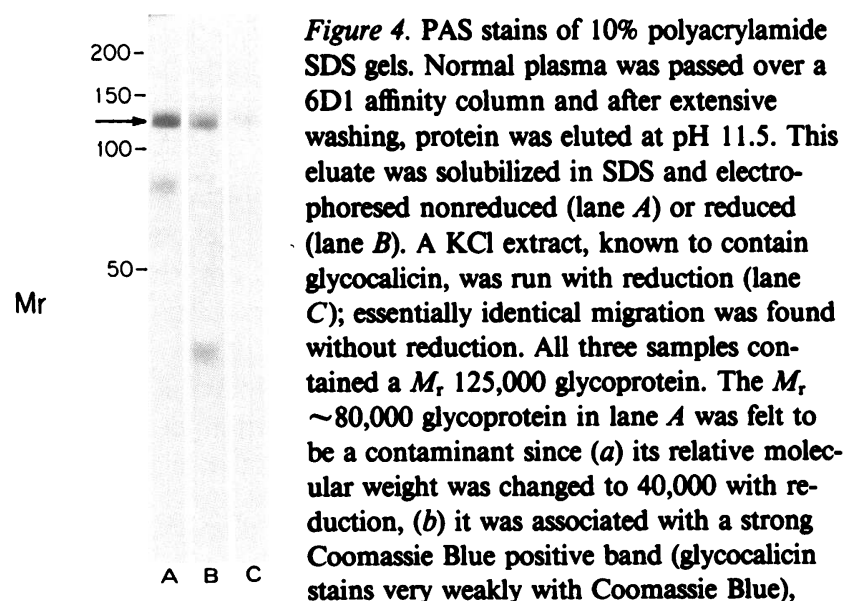

and $(c)$ chromatography of the eluate on Sephacryl S-300 revealed a single peak of immunoreactivity corresponding to the elution pattern found when the $\mathrm{KCl}$ extract was chromatographed. prolonged incubation (7); in each case, available evidence supports the proposed model. Previous in vivo studies by George et al. in rabbits indicated that there is loss of platelet membrane glycoproteins with aging, although they did not find selective loss of GPIb (12).

The current study employed our monoclonal antibody (6D1) that blocks ristocetin-induced binding of von Willebrand factor to platelets and reacts with both glycocalicin and GPIb (9). By exploiting the known differences in electrophoretic mobility of glycocalicin and GPIb (4), we designed a system in which a heterologous anti-glycocalicin immunoglobulin fraction (used to precipitate any GPIb or glycocalicin) and radiolabeled 6D1 (which is nonprecipitating) are used in concert to achieve both high sensitivity and specificity in detecting GPIb and glycocalicin. Quantitation was achieved with an immunoradiometric assay and normal plasma was found to contain 1-3 $\mu \mathrm{g} / \mathrm{ml}$. Gel chromatography and affinity chromatography were used to confirm that the plasma antigen had a relative molecular weight similar to that of glycocalicin.

Glycocalicin was consistently identified in plasmas from normal individuals. It is unlikely that the glycocalicin identified resulted from the presence of residual platelets, since $(a)$ centrifugation at forces in excess of those needed to sediment both platelets and the recently described platelet membrane microparticles (13) did not reduce the amount of glycocalicin; $(b)$ purposeful contamination of plasma with platelets did not produce an enhanced glycocalicin arc in immunoelectrophoresis, and $(c)$ patients with some diseases causing profound thrombocytopenia had normal levels of plasma glycocalicin. We also took measures to minimize in vitro proteolysis by drawing the blood directly into $\mathrm{PGE}_{1}$ and agents known to inhibit proteolysis of GPIb $(4,7,14)$; again, there were no differences in the observed arcs. On the other hand, dibucaine treatment and freezing and 
thawing platelets are known to decrease platelet GPIb, and they were associated with increased glycocalicin in the plasma.

Plasma from a patient with severe thrombocytopenia due to aplastic anemia had virtually no detectable glycocalicin, suggesting that plasma glycocalicin is derived from the catabolism of platelet GPIb. The patient with acute idiopathic thrombocytopenic purpura had a platelet count $\sim 1 / 50$ that of normal and a glycocalicin level in the low normal range, and the patient with hemolytic-uremic syndrome had a platelet count $\sim 1 / 10$ that of normal and a glycocalicin level in the high normal range. Thus, the glycocalicin level does not seem to be simply a reflection of the peripheral platelet count. Our preliminary data lead us to suspect that plasma glycocalicin levels reflect a complex function of platelet mass, platelet turnover, and perhaps, the site of destruction (intravascular or extravascular); differences in glycocalicin clearance may also affect the level. Extensive clinical studies will be required to define these relationships. Finally, while we believe that it is reasonable to hypothesize that the platelet-derived, calcium-dependent protease is responsible for the proteolysis of platelet GPIb, we wish to stress that the current studies do not directly address the identity of the in vivo protease(s).

\section{Acknowledgments}

We want to thank Joan Kiely for outstanding technical assistance and Shirley Murray for outstanding secretarial help.

This work was supported, in part, by grants from the National Heart, Lung and Blood Institute (HL19278), by a Grant-in-Aid from the American Heart Association, and with funds contributed in part by the American Heart Association, Suffolk County Chapter, New York.

\section{References}

1. Phillips, D. R. 1980. An evaluation of membrane glycoproteins in platelet adhesion and aggregation. Prog. Hemostasis Thromb. 5:81110.

2. Clemetson, K. J., H. Y. Naim, and E. F. Luscher. 1981. Relationship between glycocalicin and glycoprotein $\mathrm{Ib}$ of human platelets. Proc. Natl. Acad. Sci. USA. 78:2712-2716.
3. Okumura, T., C. Lombart, and G. A. Jamieson. 1976. Platelet glycocalicin II. Purification and characterization. J. Biol. Chem. 251:5950-5955.

4. Solum, N. O., I. Hagen, C. Filion-Myklebust, and T. Stabaek. 1980. Platelet glycocalicin: its membrane association and solubilization in aqueous media. Biochim. Biophys. Acta. 597:235-246.

5. Phillips, D. R., and M. Jakabova. 1977. $\mathrm{Ca}^{2+}$-dependent protease in human platelets. Specific cleavage of platelet polypeptides in the presence of added $\mathrm{Ca}^{2+}$. J. Biol. Chem. 252:5602-5605.

6. Berndt, M. C., and D. R. Phillips. 1981. The use of proteolytic probes to identify platelet membrane receptors. Thromb. Haemostasis. 46:75. (Abstr.)

7. Coller, B. S. 1982. Effects of tertiary amine local anesthetics on von Willebrand factor-dependent platelet function: alteration of membrane reactivity and degradation of GPIb by a calcium-dependent protease(s). Blood. 60:731-743.

8. George, J. N. 1976. Platelet membrane glycoproteins: alteration during storage of human platelet concentrates. Thromb. Res. 8:719724.

9. Coller, B. S., E. I. Peerschke, L. E. Scudder, and C. A. Sullivan. 1983. Studies with a murine monoclonal antibody that abolishes ristocetin-induced binding of von Willebrand factor to platelets: additional evidence in support of GPIb as a platelet receptor for von Willebrand factor. Blood. 61:99-110.

10. Nurden, A. T., T. J. Kunicki, D. Dupuis, C. Soria, and J. P. Caen. 1982. Specific protein and glycoprotein deficiencies in platelets isolated from two patients with the gray platelet syndrome. Blood. 59:709718.

11. Michelson, A. D., B. Melnick, J. Loscalzo, B. S. Coller, and R. I. Handin. 1983. Partial characterization of a binding site for von Willebrand's factor on glycocalicin. Blood. 62:262a. (Abstr.)

12. George, J. N., P. C. Lewis, and D. A. Sears. 1976. Studies on platelet plasma membranes. II. Characterization of surface proteins of rabbit platelets in vitro and during circulation in vivo using diazotized

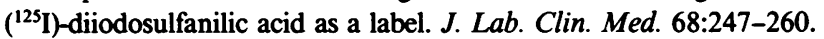

13. George, J. N., L. L. Thoi, L. M. McManus, and T. A. Reimann. 1982. Isolation of human platelet membrane microparticles from plasma and serum. Blood. 60:834-840.

14. Solum, N. O., T. M. Olsen, G. O. Gogstad, I. Hagen, and F. Brosstad. 1983. Demonstration of a new glycoprotein Ib-related component in platelet extracts prepared in the presence of leupeptin. Biochim. Biophys. Acta. 729:53-61. 